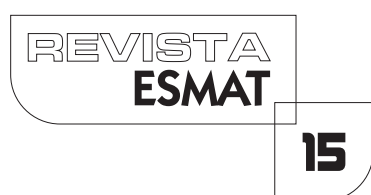

\title{
POBREZA X INCLUSÃO SOCIAL: DILEMAS E DESAFIOS POLÍTICO, SOCIAL E AMBIENTAL
}

\author{
POVERTY X SOCIAL INCLUSION: POLITICAL, SOCIAL AND ENVIRONMENTAL
}

DILEMMAS AND CHALLENGES

Ma. do Perpétuo Socorro Rodrigues Chaves

Docente da Universidade Federal do Amazonas; graduada em Serviço Social; mestre em Sociologia Rural, doutora em Política Científica e Tecnológica (UNICAMP) e em Processus d'Inovation Changements Organisationnel no Centre International de Recherche Sur l'Environnement et le Devellopment (CIRED), Paris/França. Coordena o Grupo Interdisciplinar de Estudos Socioambientais e de Desenvolvimento de Tecnologias Apropriadas na Amazônia (Grupo Inter-Ação); pró-reitora de Inovação Tecnológica da UFAM (de set./20 I I a jun./20 I7); coordena o Parque Cientifico e Tecnológico para Inclusão Social/UFAM/MCTIC e o Observatório de Economia Criativa do Estado do Amazonas, Bolsista Produtividade CNPq.

\section{RESUMO}

Este artigo trata sobre as condições de empobrecimento e exclusão social, na qual se encontram vastos segmentos sociais em todos os quadrantes do Planeta. $\bigcirc$ principal objetivo é identificar os dilemas e desafios políticos, sociais e ambientais vigentes e discutir as estratégias e mecanismos adotados para promoção da inclusão social, via cidadania e desenvolvimento com sustentabilidade. A pobreza e a exclusão social são tratadas de forma estrutural e integrada, numa crítica à lógica assistencial e voltada para uma lógica de integração social e de universalização de direitos e oportunidades, numa crítica às intervenções que visam apenas atenuar ou minimizar os efeitos sociais da pobreza.

PALAVRAS-CHAVE: Exclusão Social; Cidadania; Pobreza; Protagonismo Social.

\section{ABSTRACT}

This article deals with the conditions of impoverishment and social exclusion, in which there are vast social segments in all the quadrants of the planet, the main objective is to identify the current political, social and environmental dilemmas and challenges and to discuss the strategies and mechanisms adopted to promote of social inclusion, via 
citizenship and sustainable development. Poverty and social exclusion are treated in a structural and integrated way, in a critique of the logic of care and focused on a logic of social integration and universalization of rights and opportunities, in a critique of interventions that aim only to reduce or minimize the social effects of poverty.

KEYWORDS: Social Exclusion. Citizenship. Poverty. Social Protagonism.

\section{NOTAS CONCEITUAIS SOBRE DIREITOS HUMANOS, IGUALDADE, DIGNIDADE E CIDADANIA}

As fronteiras da modernidade ancoram trazendo consigo inúmeros desafios, dentre eles destaca-se o acirramento das desigualdades que vigem na sociedade moderna. A conjuntura contemporânea expõe imensos dilemas e reptos em face da condição de empobrecimento de vastos segmentos populacionais e grupos étnico-raciais que estão alijados do acesso a Bens e Serviços Sociais, padecendo situação de exclusão e/ou usufruto de políticas públicas que atendem de maneira precária às suas necessidades.

$\bigcirc$ imperativo inerente ao processo de transformações avassalador por seu ritmo acelerado, contínuo e crescente, associa-se às desigualdades que se enraizaram ao longo da história nas formações político-territoriais àquelas emergentes pelo (in)fluxo da sociedade moderna. O referido processo delineia a complexidade para a materialização e afirmação dos Direitos Humanos.

A sociedade na Era da Informação ou do Conhecimento (Manuel Castells) caracteriza-se pela configuração de uma grave crise econômica e socioambiental, ao mesmo tempo em que vivencia extensa e intensa revolução tecnológica, da produção de conhecimentos e informações. Dentre as diversas manifestações (interações e reações) constata-se o apogeu dos movimentos culturais, de novas estruturas sociais, inovadoras e criativas demarcações culturais em todos os quadrantes do Planeta. Igualmente, a sociedade é perpassada em todas as direções por múltiplas redes que interagem, sob variadas formas, com novas dinâmicas econômicas, culturais, em que a virtualidade do real ganha força via complexo informacional global.

A sociedade contemporânea sob a égide do neoliberalismo é (de)marcada pela redução de recursos para a viabilização das políticas públicas, por práticas de corrupção disseminadas (institucionalizadas) que determinam a negação de direitos de cidadania para vastos segmentos sociais, ampliando o grau de pauperização e desigualdades sociais.

A modernidade, sob os marcos da globalização, não alcançou a superação dos conflitos, perseguições e guerras motivadas por diferenças de identidade étnica, cultural e religiosa. $\bigcirc$ combate à injustiça, via efetivação dos Direitos Humanos, como instrumento para alcançar o desenvolvimento com sustentabilidade pressupõe a criação de estratégia de erradicação da pobreza a partir de avanços nos sistemas de proteção social das pessoas e do meio ambiente e pelo acesso à educação, à tecnologia e à 
informação.

A Cidadania e os Direitos Humanos, no contexto da história, seguem uma trajetória evolutiva organizada por fase/geração/dimensão: a primeira ocorreu no século XVIII, receberam a marca dos Direitos Individuais e sob suas premissas foram criadas as Constituições Americana e Francesa, marcadas pela luta dos direitos individuais ou direitos de liberdade; a segunda, ocorrida nos séculos $X I X$ e $X X$, marcou a defesa dos Direitos Sociais, que serviu de referência para a Constituição Mexicana, o Estado do Bem-Estar Social (Welfare State), período marcado pela luta por direitos sociais, ou seja, direitos de igualdade, direitos que foram adquiridos mediante lutas sociais acirradas, via revoluções burguesas, movimento operário e socialista nos séculos XIX até meados do $X X$, garantidas pelas leis, e da efetivação de políticas públicas; a terceira, contextualizada nos finais do século $X X$, abrange os Direitos Internacionais e está expressa na Declaração Universal dos Direitos Humanos, de 1948. E a Declaração dos Direitos dos Povos, de 1976, demarca a luta pelos direitos das minorias, do meio ambiente equilibrado, da autodeterminação dos povos; a quarta, conquistada no século XXI, abrange os Direitos Planetários e está expressa na Carta da Terra e na ECO 92, Rio + 20, expressão da luta dos povos pelo desenvolvimento sustentável.

Os direitos humanos são classificados em: I liberdades individuais - direitos civis (liberdades de locomoção, propriedade, segurança, acesso à justiça, associação, opinião e expressão, crença religiosa, integridade física); 2. dos direitos sociais - direitos ligados ao mundo do trabalho (salário, jornada, seguridade social, férias, previdência), caráter social geral (educação, saúde, habitação, lazer, segurança), marcados pelas lutas dos trabalhadores - direitos de cidadania; 3. dos direitos coletivos da humanidade - meio ambiente, paz, desenvolvimento, autodeterminação dos povos, patrimônio científico, cultural e tecnológico, direitos sem fronteiras e transfronteiriços, solidariedade planetária (testes nucleares, devastação florestal, poluição industrial e contaminação das águas, controle de patentes de remédios), ameaças entre as nações, fluxos migratórios, direitos atuais e das gerações futuras; a igualdade democrática preconiza: igualdade diante da lei, ou seja, sob o pressuposto da aplicação efetiva da lei, para proteção ou punição (isonomia); a igualdade na participação política (isegoria); a igualdade de condições socioeconômicas básicas que compreende as garantias da dignidade humana.

Os valores basais afirmados na Declaração Universal dos Direitos Humanos (DUDH), pacto consolidado em 1948 no âmbito da ONU, assumidos pelos países democráticos, servem como referência de ética e de valores socialmente desejáveis. Conforme consta no preâmbulo da Carta da ONU que introduz a DUDH, defende-se: a promoção do progresso social e de melhores condições de vida dentro de uma liberdade ampla para todos os povos; o fortalecimento de uma cultura de direitos humanos e o emprego de mecanismos internacionais para promover o progresso econômico e social de todos os povos. Pois, de acordo com os pressupostos afirmados, os Direitos Humanos são direitos fundamentais do ser humano, que deve defendê-los e usufruir deles em todos os momentos de sua vida (Cf. Gráfico I). 
Gráfico I - Áreas de abrangência dos Direitos Humanos

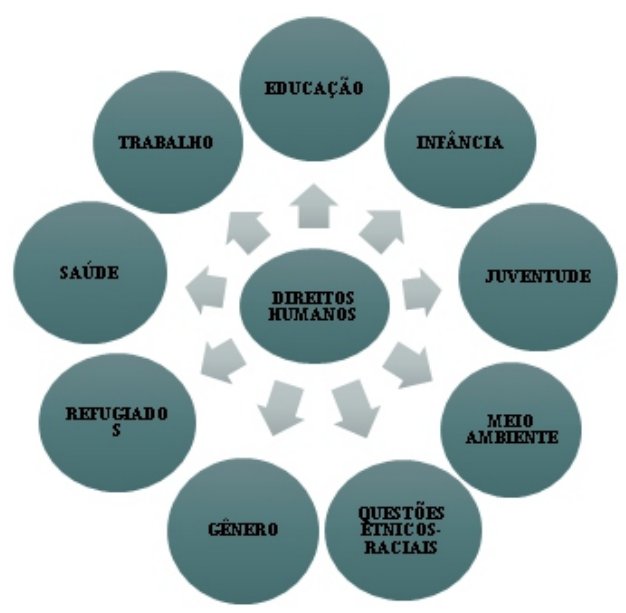

Vale enfatizar que os direitos reconhecidos ao longo da história e das lutas travadas não são superados/excluídos do escopo geral com a chegada de uma nova geração, os direitos precedentes continuam incorporados na geração seguinte. Contudo, a Declaração preconiza a relação democrática entre os direitos e liberdades individuais e os deveres para com a comunidade em que se vive.

Nas últimas três décadas, em todos os quadrantes do Planeta, houve progressos importantes no desenvolvimento humano, mas os ganhos não têm sido universais, alguns grupos sociais e países não têm conseguido se beneficiar desses avanços. $\bigcirc$ núcleo fundante dos direitos humanos é o direito à vida, tendo como prerrogativa a dignidade.

Os estudos e textos normativos nacionais e internacionais de defesa dos direitos humanos explicam a dignidade pela própria transcendência do ser humano, ou seja, o homem em sociedade instituiu os direitos, assim como a ideia de dignidade.

Na sociedade contemporânea, ainda se faz necessária a luta de diversos segmentos em defesa de uma ordem social orientada em valores, como a justiça, a igualdade, a equidade e a participação coletiva na vida pública e política, com vida digna para todas as pessoas.

Os indivíduos, comunidades, grupos sociais ou étnicos que experimentam de maneira temporária ou permanente, num determinado tempo histórico ou numa conjuntura social específica, por sua origem, pertencimento ou identificação, padecem da condição de vulnerabilidade social.

A terminologia vulnerabilidade social exprime uma condição de indivíduos ou coletivo de sujeitos que estão com dificuldades, comuns, especiais e/ou peculiares, de exercitar com plenitude sua condição de cidadania, ou seja, de usufruir os direitos que possuem e que são reconhecidos pelo ordenamento constitucional e jurídico do País. 
Poderão constituir causas de vulnerabilidade social, entre outras, as seguintes: idade, gênero, incapacidade em função de estado físico ou mental, ou por circunstâncias sociais, econômicas, ambientais, étnicas e/ou culturais como a pertença a comunidades indígenas ou a minorias, a vitimização, a migração e o deslocamento interno, perante o sistema de justiça, e também pela pobreza como resultado do empobrecimento material e/ou imaterial.

A relação daqueles que estão sob o jugo de alguma forma de opressão ou negação de direitos que os insere ao seu grupo na situação ou condição de vulnerabilidade é muito extensa e variada, possui pesos distintos e relativos, de acordo com o contexto histórico, geopolítico e social. Todavia, para fins didáticos neste trabalho, alguns critérios identificadores foram delineados a partir da identificação apresentada na literatura e nos debates de entidades e agências de credibilidade que atuam nesta área. Sob essa premissa, foram tomados como critérios identificadores de referência aqueles indivíduos/grupos que:

- enfrentam situação de carência de bens e serviços sociais pela falta ou precariedade no atendimento e assistência de diversas ordens (saúde, educação, justiça, trabalho);

- padecem de discriminação negativa por estigmas e preconceitos (materiais e/ou simbólicos);

- possuem condição desigual negativa e constituem segmentos mais numerosos;

- alcançam maior visibilidade cultural, social, econômica e política, independentemente do quantitativo do contingente;

- atuam de maneira dinâmica e/ou organizada para arregimentar aliados em diferentes setores e conseguem pautar suas demandas no poder público;

- encaram um grau muito elevado de privações de diverso bens e serviços sociais.

Os critérios relacionados como identificadores podem ocorrer de forma isolada ou simultânea na existência de indivíduos/grupos, assim como a ocorrência pode ser local ou estar disseminada de maneira transversal por diversos quadrantes, regiões, países. As entidades e instituições que atuam num amplo espectro de políticas públicas e direitos humanos, em diferentes níveis municipal, nacional e multilateral, em âmbito local e/ou global, relacionam um conjunto de indivíduos e/ou coletivos sociais que padecem da condição de vulnerabilidade, e dentre os principais estão: refugiados, quilombolas, indígenas, ciganos, afrodescendentes, assentados e acampados rurais, deslocados internos, população em situação de rua, LGBT, trabalhadores em condição de exploração por trabalhos forçados e insalubres, desaparecidos forçados, catadores de materiais recicláveis, portadores de HIV, vítimas de catástrofes.

No que tange à percepção dos determinantes que geram as formas de vulnerabilidade vigentes na contemporaneidade, além da ocorrência de fatores objetivos tangíveis vigoram também aqueles de ordem intangível. Todavia, entende-se que no patamar da existência e da experiência vivida e sentida estão imbricados e são 
indissociáveis. Nesse domínio, os valores em seu espectro imaterial, condicionado por fatores materiais/tangíveis, possuem funções basilares. De acordo com essa premissa, a dignidade humana, como fator valorativo, alcança centralidade.

A dignidade humana é expressa em práticas, comportamentos, atitudes e valores, cada cultura interpreta um fato ou condição como fator contribuinte, ou não, para a dignidade da pessoa. A dignidade do ser humano não repousa apenas na racionalidade, no plano material, mas atinge a emoção (corações e mentes), e a subjetividade. Pois se deve considerar que o homem é um ser essencialmente moral, ou seja, o seu comportamento racional está sempre sujeito a juízos sobre o bem e o mal. O ser humano tem a sua dignidade expressa, única e exclusivamente, pela pessoa humana nenhum outro ser no mundo faz projeção do dever-ser, da prática do bem ou do mal pois apenas o ser humano é dotado de vontade, de preferências valorativas, de autonomia, de autoconsciência.

Ao tomar como referência essa visão de mundo, entende-se que a pobreza é uma condição criada no âmbito das relações sociais de produção. Outrossim, observar suas expressões, configurações e transmutações ao longo da história pode inferir que a condição de empobrecimento é marcada pela discriminação de gênero, de raça, classe social e outras formas, cujos multiformes agravos variam desde o preconceito velado até a humilhação em suas várias formas de manifestação (física, espiritual, moral), geradas pela exploração do forte sobre o fraco, entre ricos e pobres, entre detentores do poder econômico e trabalhadores.

Se o pressuposto dos Direitos Humanos é o direito à vida digna, uma sociedade democrática não pode abrigar nem admitir, em seu seio, as práticas de castigos cruéis e degradantes, a exploração do trabalho, a precariedade ou a falta de acesso a bens e serviços sociais (educação, saúde, assistência social), haja vista tais práticas atentarem frontalmente contra a dignidade da pessoa e comprometerem diretamente o direito à vida digna.

Faz-se imperativo reconhecer o valor da igualdade como princípio fundador da democracia e dos direitos humanos e reconhecer a pobreza como representação da negação de direitos. A afirmação dos direitos políticos, econômicos e sociais é condição essencial para a realização da igualdade e liberdades - e não o contrário. A pobreza representa um desafio frontal aos Direitos Humanos, um atentado contra a vida com dignidade.

A desigualdade impõe uma hierarquia entre os seres humanos, em termos de dignidade ou valor; demarca uma valoração positiva ou negativa no campo social e humano; delimita a condição inferior e superior de uns em relação aos outros. A desigualdade é instituída sob a base da ideologia da superioridade inerente/intrínseca de uns sobre os outros. Enquanto que a defesa dos Direitos Humanos implica o reconhecimento de que as diferenças entre os seres humanos não podem determinar nem justificar, sob hipótese alguma, uma relação de verticalidade, de dominação.

A diferença entre povos, culturas e numa mesma formação social entre pessoas não pode determinar uma condição de desigualdade. A DUDH preconiza que Todas as 
pessoas nascem livre e iguais em dignidade e direitos. São dotadas de razão e consciência e devem agir em relação umas às outras com espírito de fraternidade.

Na Declaração Universal dos Direitos Humanos, o direito à igualdade implica o direito à diferença. A igualdade, afirmada na proposta da cidadania democrática, não significa uniformidade de todos os seres humanos, mas compreende a expressão e o respeito às diferenças étnicas, de gênero, da cor da pele, de cultura, religião e outras. As diferenças, em geral, enriquecem uma formação sócio-histórica, enquanto uma desigualdade pode ser um crime.

Para o exercício da igualdade na dignidade, ou seja, para a dignidade ter caráter democrático e universalizante, torna-se imperioso o direito à diferença. Quando as características identitárias de determinado segmento são ignoradas ou contestadas, o direito à diferença deve ser acionado em caráter protetivo. Segundo Almeida (2009, p. 1 32), Na vida comunitária, o preconceito coletivo, quase sempre, implica a superposição de uma desigualdade social a uma diversidade natural existente entre os homens.

Quando as características identitárias de um grupo social são usadas como fator de exclusão e/ou discriminação, o direito à igualdade deve ser acionado em seu favor pela prática da justiça em prol da garantia da igualdade no plano da sociedade.

Numa sociedade democrática e inclusiva, os direitos humanos, indivisíveis e interdependentes em suas dimensões naturais, universais e históricas, articulam-se às conquistas de cidadania, aos ideais da Revolução Francesa de liberdade, igualdade e fraternidade (solidariedade). A natureza indivisível e interdependente dos Direitos Humanos deriva da inserção de direitos fundamentais da pessoa humana os quais não podem ser fracionados (exemplo: o respeito às liberdades individuais e a garantia dos direitos sociais), portanto, um cidadão em condição de pauperização é contrassenso e expressa o caráter contraditório do modelo de sociedade vigente.

Ao tratar sobre cidadania e direitos humanos, Nobre (201 I, p. 24) apresenta o entendimento de que os direitos relacionam-se com (...) a compreensão da cidadania, que deve ser analisada pela ótica de um contexto internacional, valorizando-se a dignidade dapessoa humana e o seu papel estatal.

A referida autora entende que a evolução dos direitos humanos acompanha a própria evolução do homem e no papel que desempenha ao longo dos séculos. Igualmente, afirma que a solidariedade deve ser entendida como parte integrante do conceito de cidadania, podendo ser entendida como o caminho da participação dos cidadãos nas instituições do Estado e na ocupação dos espaços e das instituições da sociedade civil, formando uma rede de articulação entre o Estado e a sociedade.

Entende-se que a partir da perspectiva apresentada, a cidadania compreende: a liberdade para o exercício dos direitos fundamentais como condição da pessoa que vive numa sociedade livre; a igualdade, em sua expressão, entre todos os membros da sociedade, em principio é idealizada para evitar a existência de privilégios de classes ou grupos sociais no exercício de direitos; a solidariedade compreende o sentido de pertencimento e de compromisso com os demais membros da sociedade e representa a construção de uma sociabilidade política, ou seja, uma contínua interação social de 
respeito e colaboração mútua com cada indivíduo ou coletividade com a qual se estabelece alguma forma de relacionamento.

A sociabilidade política é uma qualidade de relacionamento que respeita os demais agentes e sujeitos sociais e trata com alteridade todo ser. Instituída pelo homem em sociedade, porque apenas o ser humano, única e exclusivamente, pode experimentar, agir de maneira determinada no autoaperfeiçoamento pelo desenvolvimento de suas capacidades, virtualidades, habilidades interpretativas, abordagens explicativas, sob os marcos de juízo de valor baseados na cultura e na interação social.

O ser humano é o único ser histórico que vive em contínua transformação, que articula em sua prática aprendizado do passado, a ação presente e projeta o futuro. $\bigcirc$ ser humano denota uma unidade existencial, singular e insubstituível, cuja existência guarda valor absoluto, é um fim em si, e não um meio para outras coisas (Kant).

Ao tomar por base a sua unidade existencial, torna-se imperioso entender que o exercício da cidadania implica dupla ação, em que o indivíduo, ao tempo em que usufrui de direitos, também assume o papel de agente responsável mediante a sociedade, e a sociabilidade política é a expressão desse intercâmbio indissociável entre direitos e deveres.

O sentido e o significado da condição cidadã na contemporaneidade, sob o aporte da abordagem dos direitos, precisam ser examinados pela ótica do respeito e da valorização da pessoa humana na sua dignidade e pelo papel das políticas públicas nessa empreitada. A cidadania é a base para ter direitos na condição de cidadão, ou seja, ter acesso ao princípio da legalidade - o primeiro direito humano é o direito a ter direitos (Hannah Arendt).

A cidadania qualifica o indivíduo como partícipe da sociedade para que esta atue ativamente para sua sobrevivência digna. A contrapartida indispensável é a de que o cidadão também deve assumir responsabilidades em relação à comunidade: a sociabilidade política. Esta somente se viabiliza concretamente pela via da participação ativa no campo da concretização da política (ONU, 20 I 4).

Todo sistema ou regime, fundado sobre o princípio democrático, deve garantir a inclusão social de todos os seus membros, isso implica cidadania, a partir: da participação popular cidadã no usufruto dos direitos políticos; do acesso aos direitos sociais (trabalho, educação, habitação, saúde e assistência social); e dos direitos civis (liberdades individuais).

A condição cidadã integra os sujeitos na comunidade com a garantia dos direitos civis e políticos, mas igualmente requer também sua participação para que possa usufruir dos direitos sociais indispensáveis para uma vida digna. Assim, sob a perspectiva de cidadania universal, a cidadania é uma condição que fornece habilidades para que o indivíduo possa exercer seus direitos, e o acesso aos bens e serviços sociais são indispensáveis para que os indivíduos tenham o status de cidadãos. Portanto, o acesso à Justiça configura-se como instrumento de extrema relevância para a inclusão social, como disposição requerida de modo indispensável no processo cidadania real e inclusiva. 
Mediante a cena delineada é mister traçar um breve desenho do quadro de pobreza e exclusão social que vige na sociedade em termos globais, em seus delineamentos mais abrangentes.

\section{CARACTERIZAÇÃO DA POBREZA \& EXCLUSÃO SOCIAL NA SOCIEDADE CONTEMPORÂNEA}

avanço civilizatório da sociedade capitalista é indissociável do crescimento do meio urbano, assim marcada pela tendência mundial de crescimento das cidades, a questão do direito à moradia digna, vinculada ao direito à cidade, ganhou amplitude e complexidade. $\bigcirc$ espaço urbano ganhou mais visibilidade como escopo fundamental para o desenvolvimento mediante o quadro de: aceleração da urbanização com ampliação dos problemas demográficos pela distribuição desigual dos espaços urbanos; da intensa saída do campo para a cidade de vastos contingentes humanos expropriados e/ou em busca de acesso aos serviços e bens sociais de saúde, educação e todas as formas de assistência; o crescimento (des)ordenado das cidades sob a lógica do capital que segrega as populações pobres em áreas degradadas.

A questão social e ambiental representa uma das mais complexas problemáticas que regem o meio urbano na sociedade capitalista moderna. A cidade fundada pela lógica do capitalismo ganhou uma configuração complexa, em relação às modalidades de cidades que existiram ao longo da história em outras formas de sociedade diferenciadas do modo capitalista de ordenamento societal.

Em variados níveis de gravidade e de manifestação em cada região e/ou país, a cidade tornou-se um amálgama de dilemas e desafios, em que as diferenças econômicas, sociais e culturais existentes trazem à tona a trama da relação capital trabalho e os impactos ambientais da forma de uso dos recursos para produção e o padrão de consumo e descarte de resíduos que degradam de forma acentuada o contexto cotidiano daqueles que vivem na cidade.

Na sociedade contemporânea, as cidades viraram domínio onde se multiplicam as situações de vulnerabilidade humana, tanto no plano social quanto ambiental, com a manifestação de múltiplos fenômenos, como: gentrificação; rurbanização; conturbação; megalópoles; macrocefalismo urbano.

Esses fenômenos atingem inúmeros grupos sociais que passam a fazer parte do contingente de sem teto (população de rua), sem emprego (fora do mercado de trabalho formal), sem terra (camponeses), sem pátria (expatriados/refugiados). Indivíduos que coadunam não apenas com uma das condições relacionadas, mas que experienciam diversas ou até mesmo o conjunto delas oriundo da desestruturação das organizações tradicionais expressão do êxodo rural gerado pela expansão das relações capitalistas modernas. Assim, surgem e aumentam os contornos de um extenso contingente que vivencia carências extremas, ou seja, padecem do processo de absolutização do empobrecimento. 
Um dos pontos críticos da sociedade contemporânea está relacionado ao uso dos recursos da biodiversidade e aos ecossistemas, que envolve desde intenso consumo dos recursos não renováveis, as formas de depredação, o excesso de desperdício dos recursos renováveis, as formas de descarte dos resíduos da produção e do consumo, até a busca incontrolada do lucro, da produtividade, da competitividade (Ver Gráfico 2).

Gráfico 2 - Esquema da sociedade contemporânea

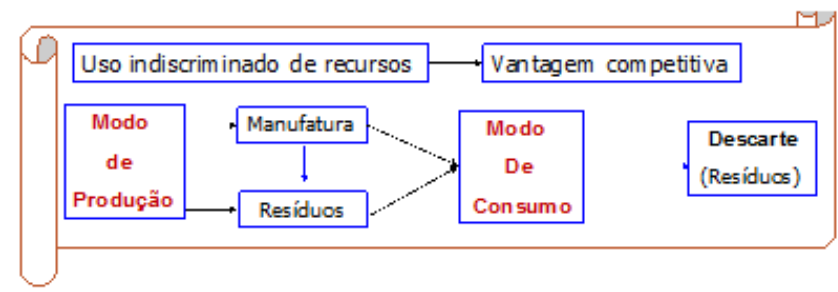

Embora ainda pese a controvérsia no campo científico entre os que defendem como processo natural as mudanças climáticas que estão ocorrendo no Planeta, aumentam as comprovações de que o processo é gerado pelo modelo civilizatório. Entende-se que sob a lógica do capital e dos fundamentos da ciência moderna (modelo de ciência), a relação dos homens entre si e com a natureza na sociedade urbano-industrial, é uma relação de dominação que redunda na crise socioambiental que predomina em âmbito global. A questão do meio ambiente abrange um conjunto complexo de dilemas e desafios que compromete o desenvolvimento da sociedade.

Dentre as principais questões a serem ressaltadas, ao se considerar a questão ambiental na cena societal, destacam-se: os problemas de falta de investimento para proteção das Unidades de Conservação e de uso sustentável; descontrole e políticas que favorecem as práticas desenfreadas de desmatamento e emissão de gases nocivos na atmosfera; a falta de controle ao impacto causado por substâncias e resíduos nocivos ao meio ambiente e à saúde; o descaso com a conservação das espécies ameaçadas e de importância socioeconômica; a falta de ações efetivas para controle dos agentes que aceleram as mudanças climáticas e gestão de riscos de desastres naturais; a falta de políticas e ações institucionais na construção e/ou identificação dos critérios, instrumentos e práticas de sustentabilidade.

Nessa cena observam-se os limites das agências multilaterais de conseguirem o cumprimento das metas de proteção dos tratados e acordos firmados entre as nações em relação ao controle das práticas predatórias que extrapolam as fronteiras nacionais. Os impactos ambientais atingem todos, porém impactam ainda mais os que estão em condição de maior empobrecimento e vulnerabilidade, ameaçam seus direitos à vida digna, e são contemplados por respostas limitadas de governos, empresas e cidadãos. As estimativas apontam que cerca de 19 milhões de mortes prematuras ocorram por ano devido à forma como as sociedades usam recursos naturais para a produção e consumo e afetam os ecossistemas (ONU, 20 I 6). 
No campo cientifico, ampliam-se as comprovações em relação ao aumento dos gases de efeito estufa que geram o aquecimento global pelas ações antrópicas, como: as atividades produtivas industriais, agrícolas, meios de transporte e descarte de consumo residencial. Essas atividades geram fortes impactos pela deposição de resíduos tóxicos que ocasionam diversas formas de poluição (do ar, dos rios, córregos) com grau elevado de contaminação dos mananciais e extinção das nascentes pela concentração da poluição por esgoto nos períodos de estiagem, de modo a gerar degradação e infertilidade dos solos, perda de plantações pelo uso intensivo de agrotóxicos, da criação de gado, cultivo de arroz, desmatamento e queima de florestas e vegetações, uso intensivo do solo, queima de combustíveis fósseis (petróleo, gás natural e biomassa carvão vegetal).

A intensificação das mudanças climáticas no Planeta promove e/ou acelera variadas transformações como resultado do aquecimento global, dentre eles: o derretimento da calota polar, com icebergs que ficam à deriva; as alterações nos ecossistemas com extinção de espécies animais e vegetais; as variações danosas no ciclo das águas (seca, enchente, cheia e vazante); o aumento das catástrofes (furacões, tsunamis, incêndios, tornados); as alterações na temperatura das águas que alteram a intensidade dos ventos alísios e das correntes marítimas e o ciclo de vida das espécies; as mudanças na maturação das plantas, com ocorrência de pragas; o grau de umidade dos solos que afeta o regime de chuvas, a produtividade das pradarias e pastagens; o descontrole de temperatura tem sua incidência potencializada gerando a emergência de doenças e ressurgimento de outras já erradicadas pela propagação de vetores.

A crise socioambiental enfrenta um quadro crítico em relação à contaminação e escassez global de água. Em países em desenvolvimento, 90-95\% dos esgotos residenciais e $70 \%$ dos resíduos industriais são despejados, sem tratamento, em águas que poderiam ser usadas em abastecimento. Mais de 250 milhões de pessoas/ano são afetadas por doenças ligadas à água (50\% leitos em hospitais). Mais de 6.000 crianças morrem por dia de doenças ligadas à água; mais de 2,2 milhões de pessoas morrem por ano, maioria crianças, de doenças associadas à água e saneamento; em torno de $18 \%$ da população terrestre ( I , I bilhão), não têm acesso à água potável (ONU, 20 | 6).

Sob o enfretamento do grau mais acentuado desses impactos estão os segmentos de países com baixo grau de desenvolvimento. Na lista de países considerados como menos desenvolvidos, figuram 47 países com mais de 880 milhões de pessoas, ou seja, cerca de $10 \%$ da população mundial.

Dentre as diversas transformações que transmutam a sociedade contemporânea, as famílias enfrentam fortes e aceleradas mudanças. Os arranjos domiciliares de casais com filhos deixaram de ser maioria absoluta; cresceu o percentual de casais sem filhos, famílias monoparentais com alta predominância de mulheres sozinhas responsáveis pela criação dos filhos, coabitação marital, famílias formadas por casais homoafetivos e pessoas vivendo sozinhas.

Os estudos sobre a sociedade global, bem como muitos estudos de caso (CHAVES, 
2016; 2017) indicam como as formas como as pessoas lidam com os desafios do trabalho e da vida familiar são marcadas pelas desigualdades de gênero. A violência contra as mulheres é uma questão social grave e com consequências diretas na vida em geral e na saúde sexual e reprodutiva. Todavia, a realidade da violência doméstica é pouco conhecida, existem muitas barreiras para mapear a situação existente, de falta ou incompletude de registros da agressão, pois, na maioria das vezes, as ocorrências não são denunciadas às instituiç̧̃̃es e às autoridades responsáveis.

A situação das mulheres não é uma questão conjuntural, mas é enraizada, mantida, encoberta e forjada no âmbito societal pelo modelo de organização da sociedade. Daí advém a dificuldade de as mulheres buscarem apoio para denunciar, principalmente pela forma mais comum de violência contra elas ser o abuso por parte do companheiro (agressão psicológica, física, sexual, emocional). Por isso, torna-se difícil até mesmo o apoio da família, gerando uma situação de silêncio e aceitação, o que propicia e alimenta a continuidade das agressões que avançam e se agravam mais e mais.

Em vários países latino-americanos, a violência não é somente praticada, mas também reconhecida e legitimada por parte da sociedade, principalmente quando envolve infidelidade conjugal. Esse quadro socioinstitucional configura-se em mais de I 50 países nos quais vigora pelo menos uma lei que legitima a discriminação das mulheres.

Entretanto, de forma notória, a violência contra as mulheres não se encerra nos espaços domésticos, a violência sexual e a institucional também se mostram presentes em todas as esferas, e até nas formas diversificadas de exploração laboral. Em várias nações, as mulheres têm menos oportunidades para votar, daí a baixa representação em cargos públicos e a dificuldade para conter as leis e políticas discriminatórias.

\section{POBREZA\& EXCLUSÃO SOCIAL: DILEMAS E DESAFIOS BRASILEIROS}

No Brasil, no processo de constituição da nação, as classes proprietárias que se perpetuaram dando bases para as atuais elites políticas (agrárias, industriais, comerciais), mediante o processo de colonização do País, não lutaram em defesa de liberdades civis e políticas que eram negadas ao povo brasileiro - não existiu uma "revolução burguesa". (Konder Comparato).

As forças advindas das lutas populares e de trabalhadores atuaram para as mudanças institucionais no País e conduziram para a constituição dos determinantes para formação sócio-histórica brasileira, em que pese à prevalência dos interesses das classes proprietárias na condução das instituições responsáveis pelas políticas públicas e sociais.

Adicionalmente, no Brasil, o padrão que moldou a formação do País limitou o avanço das conquistas democráticas, somente no século $X X$ a consciência da dignidade humana, da liberdade, da igualdade, da solidariedade, associada aos direitos sociais, ao mundo do trabalho e ao direito à educação passaram a ganhar terreno. Todavia, ao considerar os últimos 25 anos, é possível identificar alguns avanços, conforme pode ser 
observado no Quadro 01 .

Quadro 01 - Avanços Sociais do Brasil no período de 1990 a 2015

\begin{tabular}{|c|c|c|c|c|}
\hline Avanços do Brasil & Expectativa de vida & Renda & \multicolumn{2}{|c|}{ Educação } \\
\hline $1990-2015$ & $+9,4$ anos & $31,6 \%$ & $\begin{array}{c}\text { Criança }(+3 \text { anos } \\
\text { de estudo })\end{array}$ & $\begin{array}{c}\text { Adultos a partir } \\
\text { de } 25 \text { anos } \\
(+4 \text { anos })\end{array}$ \\
\hline
\end{tabular}

Na conjuntura atual, a crise política e econômica que o Brasil enfrenta contribuiu para a vigência de estagnação que ocorre desde 2014 nos Índice de Desenvolvimento Humano (IDH) do Brasil (ONU, 20 I 6) (Cf. Quadro 02).

Quadro 02 - Brasil no Rank do Índice de Desenvolvimento Humano (IDH)

\begin{tabular}{|c|c|c|}
\hline IDH do Brasil & Rank América Latina & Rank Mundial \\
\hline $\begin{array}{l}0,754 \text { (estagnado desde } \\
2014 \text { ) }\end{array}$ & $\begin{array}{c}1^{\circ} \text { Argentina; } 2^{\circ} \text { Chile; } 3^{\circ} \text {. } \\
\text { Uruguai; } 4^{\circ} \text { Venezuela*; } 5^{\circ} \text { Brasil }\end{array}$ & $79^{\circ}$. (entre 188 países) \\
\hline
\end{tabular}

Ao considerar os Índices de Desigualdade de Gênero no Brasil (ONU, 20 I6), no caso específico do mercado de trabalho, em relação à qualificação profissional + de $70 \%$ dos brancos são classificados como trabalhadores altamente qualificados, para $30 \%$ entre os negros brasileiros.

Observa-se que, em relação à média salarial, as pessoas com deficiência possuem menos de $40 \%$ de participação na força de trabalho e percebem em torno de $70 \%$ pelo mesmo tipo de serviço. No caso dos indígenas, para a mesma função/cargo eles recebem em média $60 \%$ do que aqueles tidos como brancos recebem.

Ao contemplar os Índices de Desigualdade de Gênero no Brasil (ONU, 20।6), inúmeras faces das desigualdades se revelam nas áreas da saúde reprodutiva, atividade econômica, participação política e econômica das mulheres (Cf. Quadro 03).

As pesquisas sobre percepção e experiência de violência apontam que $40 \%$ das mulheres brasileiras afırmam já ter sofrido violência por parte de um homem; I $8 \%$ relatam sofrer ou ter sofrido violência doméstica. Entre 2003 e 2013, registrou-se no País um aumento de $21 \%$ no número de assassinatos de mulheres. O Mapa da Violência, de 2015, indicou 4.762 mortes, correspondente à taxa de 4,8 assassinatos por 100 mil mulheres. Os dados permitem perceber que a violência é ainda mais grave entre as mulheres negras, pois a taxa de assassinatos de mulheres brancas decaiu em torno de 12\%, enquanto o assassinato das mulheres negras cresceu 19,5\%. 
Quadro 03 - Índices do Brasil, na área de Educação, Renda per capita e Salário em 2016

\begin{tabular}{|c|c|c|c|}
\hline Desempenho & IDH - homens & IDH - mulheres & Rank Mundial \\
\hline $\begin{array}{c}\text { Educacional e } \\
\text { longevidade }\end{array}$ & 0,75 I & 0,754 (melhor) & $\begin{array}{c}0,414-92^{\circ} \text { (entre } \\
\text { os mais mal avaliados } \\
\text { dos I } 88 \text { países) }\end{array}$ \\
\hline Renda per capita & $\begin{array}{c}\text { U\$ I7,736 (66,2\% } \\
\text { maior que o das } \\
\text { mulheres) }\end{array}$ & U\$ I0,672 & $\begin{array}{c}\text { Menor patamar, } \\
\text { desde } 2010\end{array}$ \\
\hline Ganhos salariais & $76 \%$ & $\begin{array}{c}\text { Em média } 24 \% \text { menor } \\
\text { que os homens }\end{array}$ & \\
\hline Altos Cargos & \multicolumn{2}{|c}{$24 \%$} & \\
\hline
\end{tabular}

Em relação à participação política das mulheres no Brasil, uma comparação que mostra o quadro adverso da situação é desvelada ao comparar o percentual de assentos ocupado por mulheres no Congresso Nacional Brasileiro. Na República CentroAfricana, que possui o menor IDH do mundo, 12,5\% das mulheres conseguem assento no Parlamento, enquanto no Brasil apenas 10,8\% de mulheres chegam a ser eleitas.

Outro indicador importante que requer atenção são os índices de confiança que foram levantados nos estudos organizados no Mapa da Violência, tendo em vista que aproximadamente $50 \%$ entre a maioria étnica e $40 \%$ entre a minoria branca afirmam ter confiança nos tribunais de justiça do Brasil.

Brasil está no topo do rank mundial dos países onde ocorre maior número de mortes geradas pela prática de violência por discriminação sexual, morrem em torno de 150 pessoas por ano, com registro de um assassinato a cada três dias. A homofobia é um problema real entre a população GLBT (lésbicas, gays, bissexuais, travestis e transexuais); contudo, menos de 10\% dos assassinos de homossexuais são punidos pelo crime praticado.

No Brasil, situação de vulnerabilidade socioambiental enfrentada por vários segmentos sociais é muito acentuada e crescente mediante a acelerada dinâmica de crescimento das práticas predatórias destrutivas e geradoras de poluição dos recursos hídricos agravados pela carência de investimentos na captação, tratamento e distribuição; crescimento demográfico. Em torno de 25\% de domićlios brasileiros não são atendidos por rede de água tratada, apenas 45\% das residências brasileiras possuem coleta de esgoto (CHAVES, 20 |6).

\section{I. Proteção Social no Brasil, empreitada em prol do acesso aos direitos}

A proteção social conforma-se a partir de um conjunto de mecanismos e instrumentos de política social que possuem a competência para garantir a segurança da 
sobrevivência digna em termos de renda e autonomia dos segmentos e grupos sociais em situação de carência de qualquer ordem que limite sua condição de cidadania e negação de direitos humanos.

Assistência Social no Brasil avançou da concepção filantrópica e beneficente para pública, com caráter de direito ao amparo, a partir da instituição da garantia da Assistência Social na Constituição Federal. AAssistência Social configura-se como política social no campo dos direitos o qual integra o sistema de Seguridade Social com a Saúde e a Previdência Social como prestação de serviços estatais, com controle e responsabilidade, cujas principais diretrizes são a descentralização da assistência e a participação da população na formulação das políticas sociais.

A Lei Orgânica da Assistência Social (LOAS) possibilitou a concretização de que as ações pudessem ser viabilizadas pelo Sistema Único de Assistência Social (SUAS) nos Centros de Referência de Assistência Social (CRAS) - proteção social básica - e o CREAS -proteção social especial - a partir da premissa e fundamentos de que a Assistência Social deve ser prestada a quem dela necessitar, independentemente de contribuição à Seguridade Social.

Os principais objetivos da prestação de assistência social são: a proteção à família, à maternidade, à infância, à adolescência e à velhice; o amparo às crianças e aos adolescentes carentes; a promoção da integração ao mercado de trabalho; a habilitação e reabilitação das pessoas portadoras de deficiência e a promoção de sua integração à vida comunitária; a garantia de um salário mínimo de benefício mensal à pessoa portadora de deficiência e ao idoso que comprovem não possuir meios de prover a própria manutenção ou de tê-la provida por sua família (Lei n 8.742, de 1990 - LOAS, art. 203)

A proteção social viabilizada pelo Sistema Único de Assistência Social é seletiva, direcionada para as necessidades sociais, com vista a garantir a segurança de sobrevivência (renda e autonomia), acolhida, convívio/vivência familiar, e utilizada como instrumento direcionado para erradicação da pobreza, da marginalização e para redução das desigualdades sociais e regionais. Desse modo, a Assistência Social caracteriza-se como direito social e deve ser prestada a todos aqueles que dela necessitar por ser um direito fundamental. Deve-se considerar que não é a pobreza que gera tais direitos, mas sim a qualidade de ser cidadão que qualifica os segmentos sociais em condição de empobrecimento a serem atendidos por políticas sociais qualificadas e focalizadas.

A Política Nacional de Assistência enfoca a garantia e a afirmação do direito à proteção social, pelo direito ao acesso à seguridade social, direcionada/vocacionada para prover um suprimento padrão de existência, com superação da exclusão do acesso a bens e serviços sociais, e de desenvolvimento das capacidades das pessoas para maior autonomia e universalização dos acessos e da responsabilidade estatal. Todavia, toda a diligência prestada por esse modelo de proteção social pública viabiliza-se orientada pela associação solidária entre os entes federativos e a comunidade. 
A proteção social, por seu caráter distributivo, deve abranger diversas frentes e demandas, que envolvem desde a promoção da capacidade de acesso aos bens, serviços e recursos com bem-estar, centrada no incremento das capacidades de indivíduos e famílias.

A Política Nacional de Assistência Social igualmente prevê o enfrentamento das desigualdades socioterritoriais nos diversos contextos do País, que abrangem os domínios do campo e da cidade. Pois, o território é um espaço fundamental para o empoderamento dos grupos sociais e na instrumentalização da democracia participativa.

No Brasil, os povos e as comunidades tradicionais, que começaram a ganhar visibilidade e reconhecimento de seus direitos a partir da década de 80, ganharam mais visibilidade ao se organizarem politicamente, questionando sua expulsão de áreas que pertenciam aos seus antepassados e forneciam recursos naturais usados como principal fonte de reprodução social, contribuindo para a reorganização da sociedade civil brasileira e o reconhecimento, em âmbito internacional, da importância dessas comunidades para a conservação ambiental (Lira \& Chaves, 20 I 6).

No Brasil, as populações indígenas, desde o processo de ocupação e colonização, são vitimadas de maneiras diversas, a expropriação dos espaços de organização sociocultural gera grave desestruturação nos modos de vida e na identidade política desses povos. A redução populacional apresenta um quadro crítico, de milhões para aproximadamente 900 mil indivíduos, destes 520 mil (57,7\%) vivem em 687 terras indígenas, e 380 mil fora delas seja no campo ou na cidade. As terras indígenas abrangem 13\% do território nacional, atuam também como áreas de proteção ambiental.

Mediante o quadro vigente, a proteção social dos povos e comunidades tradicionais, indígenas e não indígenas carecem de efetivo acesso à Justiça. Para convergir nessa direção, faz-se necessário, dentre outras requisições e processos, a garantia do direito ao território. Nas circunstâncias que atingem os povos tradicionais (indígenas e não indígenas), o território possui dimensão material, funcional, associada à dimensão simbólica que incide na formatação da identidade social, na autonomia, na gestão da vida e dos ecossistemas locais (Chaves, 20 I4).

Os grupos sociais não podem prescindir do reconhecimento de sua identidade sociocultural, um exemplo notório entre os povos indígenas está na luta pelo direito ao uso da língua de sua etnia. Para esses povos, isso representa o direito à inclusão no universo da cidadania como brasileiros, na garantia do princípio da igualdade, na superação da condição e sujeição às variadas formas de preconceito e abuso, no acesso ao princípio da não discriminação.

Quanto à proteção social no caso das pessoas com deficiência, o Brasil, em que pese todos os limites e dilemas, está entre os cinco países mais inclusivos das Américas, reconhecido por sua legislação e políticas públicas voltadas para as pessoas com deficiência. Como fator diferencial está a organização de movimentos sociais, fora a ação da rede de conselhos de direitos 
Nas duas últimas décadas, o modelo com base em ações assistencialistas vem sendo substituído pelo paradigma da inclusão social, caracterizado pela construção da autonomia das pessoas com deficiência, do respeito à diversidade e à dignidade, na participação e equiparação de oportunidades, sob a perspectiva dos direitos humanos com acessibilidade física, comunicacional e atitudinal.

No Brasil, uma das transformações mais marcantes do século $X X$, em termos de mudanças sociais, econômicas e demográficas, foi a mudança no papel das mulheres, com destaque para o crescimento de famílias mantidas por mulheres. No campo da proteção social das mulheres no Brasil, a Lei Maria da Penha, promulgada em 2006, promoveu a definição para o reconhecimento dos diversificados tipos de violência praticados contra as mulheres, de ordem física, sexual, psicológica, moral e patrimonial.

A implementação da Lei tornou mais rigorosas as penas contra o agressor, determinando a criação de práticas convergentes e a busca pela articulação entre os mais diversos mecanismos e instrumentos para a viabilização de políticas públicas para a prevenção da violência, como a constituição da Rede de Atendimento à Mulher em Situação de Violência, as políticas de enfrentamento da violência, articulação entre as instituições pela prevenção da violência e implementação da Lei, a disseminação de informações à sociedade.

Os dados dos estudos contidos nos Relatórios do Quadro de Desigualdade de Raça e Gênero no Brasil constam que, entre 20 I 2 e 20 I 5, 22 milhões de pessoas superaram a pobreza extrema, dentre elas 54\% (12 milhões) são mulheres. Todavia, diversas medidas de políticas públicas e mudança social (atitudinal, comportamental e moral) ainda são necessárias para combater a situação das mulheres na sociedade brasileira.

No plano das políticas socioambientais no Brasil, destaca-se a Política Nacional de Recursos Hídricos (PNRH), que preconiza a participação, a gestão e proteção ambiental com descentralização do acesso à água como condição para a criação de oportunidades de sustento e contribuição para a produtividade. A contratualizacão entre os agentes para melhoria na gestão dos recursos hídricos e prestação de serviços pode contribuir para a redução da pobreza e prover suporte para o crescimento econômico.

Portanto, a devida e a eficaz viabilização da Política Nacional de Recursos Hídricos são imperativas, pois envolvem e servem de base para uma gama de serviços, como: desenvolvimento econômico; usos produtivos na agricultura e empresas familiares, geração de renda e produção de energia; serviços de abastecimento de água tratada para uso doméstico; saneamento público; segurança alimentar; saúde humana; bemestar social e meios de subsistência de todas as espécies; recuperação de perdas da capacidade de produção natural de água; prevenção ao assoreamento temporário ou permanente por uso irregular do solo; evitar a eutrofização dos reservatórios; prevenir o aumento da carga difusa com maior presença da cidade nas áreas de mananciais.

No campo da proteção social no Brasil, diversas medidas têm sido implementadas, em que pese ao universo de problemáticas existentes, renitentes e emergentes, e os limites detectados na viabilização das medidas protetivas. Todavia, dentre as medidas de 
maior alcance e efetividade destacam-se:

- os programas de transferência de renda (Programa Bolsa Família, Minha Casa Minha Vida), que atuam de maneira estratégica para o enfrentamento da questão da moradia;

- o crescimento do compromisso socioinstitucional com a promoção da igualdade de gênero com o combate à homofobia, à proteção aos segmentos LGBG com políticas públicas;

- a implementação integral da Lei Maria da Penha;

- a ações de prevenção ao crime e ao tráfico de pessoas;

- a política nacional para inclusão social da população em situação de rua;

- o fortalecimento da cooperação humanitária;

- a luta pela Erradicação do Trabalho Infantil (PETI);

- a lei de cotas (PROUNI, FIES) possibilitou o acesso aos indígenas, alunos de escolas públicas com a triplicação do número de jovens negros nas universidades.

Mas a constatação relatada por vários debates, estudos e percepção empírica é de que ser garantida como direito não implica a plenitude e efetividade da execução da proteção social tal como enunciada em suas diretrizes básicas e contratuais, visto que enfrenta profundas restrições orçamentárias, uma estrutura de prestação dos serviços precária. Tais condições geram um quadro adverso que demarca, em diversas situações, o caráter de benemerência, de auxílio para atenuar a pobreza e reduzir o conflito/reivindicações para reprodução da força de trabalho para o capital, o que fere frontalmente seu caráter de direito social.

\section{JUSTIÇA, IGUALDADE E PROTAGONISMO SOCIAL: MECANISMOS E ESTRATÉGIAS DE INCLUSÃOSOCIAL}

A ONU preconiza que as políticas e estratégias nacionais e globais necessárias para alcançar as populações atualmente excluídas precisam estar organizadas em quatro eixos:

I. Piso de proteção social (políticas universais de saúde e educação; de assistência social, como o Bolsa Família e o Benefício de Prestação Continuada; benefícios previdenciários para grupos vulneráveis; inclusão financeira);

II. Políticas de ação afirmativa (para mulheres, negros, indígenas, pessoas com deficiência entre outros grupos vulneráveis);

III. Desenvolvimento humano sustentável (para evitar que as crises econômicas, epidemias, desastres naturais, não gerem pobreza);

IV. Participação e autonomia dos excluídos (efetivar os tratados de direitos humanos; garantir o acesso à justiça; promover inclusão; e efetivar o direito à informação). 
Os eixos relacionados cingem condições imprescindíveis para a constituição de uma sociedade civil livre e independente, conforme explicitou Ban Ki-moon, secretário-geral das Nações Unidas, no Conselho dos Direitos Humanos (20 I 4), o qual afirmou que uma governação idônea e reativa, em âmbitos local, nacional e mundial, necessita como pilar fundamental uma sociedade civil livre e independente. Os compromissos de cada Estado/Governo com sua própria nação e as obrigações legais internacionais demandam que estes atuem na criação de condições econômicas, políticas, sociais, culturais e legais que permitam apoiar, de maneira efetiva, contínua e eficaz, as competências e as capacidades individuais e/ou coletivas.

A atuação das autoridades e da sociedade civil, de modo geral, deve ter como base para ação os princípios dos direitos humanos que regem as relações em sociedade, como:

I. Participação cidadã por meio da qual os indivíduos ou grupos exercem seu papel no âmbito societal em defesa de seus interesses, e para advogar em prol da superação das condições adversas de negação do direitos de cidadania;

2. Vigilância em prol da não discriminação, em que todos os atores da sociedade civil assumem o compromisso de reconhecer o direito à diversidade, sem que sofram qualquer tipo de discriminação;

3. Dignidade, a vigência de condições de igualdade no acesso aos bens e serviços sociais e o exercício do respeito mútuo nas relações estabelecidas;

4. Transparência e responsabilidade representam o compromisso de todos agirem em beneficio do interesse comum, com integridade, responsabilidade e ações transparentes.

Para o exercício dos princípios elencados a partir de boas práticas, faz-se necessário estabelecer ambiente político e público que favoreça, valorize e incentive a contribuição da sociedade civil, a constituição de mecanismos e ferramentas de controle social e participação cidadã. A atualização das legislações, das regras/normas administrativas e das práticas institucionais ampliando o acesso dos atores da sociedade civil à justiça e a instituições nacionais de defesa dos direitos humanos independentes.

A criação de espaços de compartilhamento de ideias, diálogo e ações colaborativas com difusão, publicização e socialização democrática de informações, de maneira que instrumentalize as iniciativas e as tomadas de decisões, com vista a permitir a informação e a sensibilização dos atores da sociedade civil, em relação às demandas e problemáticas existentes, tanto antigas quanto as emergentes. Todavia, para além de ganhar espaço de expressão é mister que lhes sejam criadas oportunidades de atuarem na formulação de alternativas. Outrossim, a visão planetária precisa ser difundida pelas informações sobre o acesso aos mecanismos internacionais dos direitos humanos. $\bigcirc$ subsecretário-geral para o Desenvolvimento Econômico e Social, Wu Hongbo, afirmou que os objetivos de desenvolvimento sustentável partem do reconhecimento de que o desenvolvimento só será sustentável se for inclusivo.

No caso específico da questão de gênero, em diversas partes do mundo ocorrem movimentos organizados em favor de mudanças socioinstitucionais gerando rupturas 
em alguns dos privilégios masculinos na família e na sociedade com a concessão de crescentes direitos às esposas e aos filhos. Além de passarem a vigorar inúmeras mudanças nas regras de casamento e de parceria sexual no tocante às relações de gênero. Todavia, a alteração do papel da mulher de coadjuvante nas decisões familiares e na sociedade, em termos globais e institucionais, ainda requer uma longa trajetória de avanços e conquistas.

Nessa direção, diversos movimentos organizados lutam pelo estabelecimento de princípios de empoderamento político, econômico e social das mulheres em termos globais, para: o exercício de liderança em igualdade de gênero; isonomia salarial entre homens e mulheres de forma justa no trabalho; pleno acesso à saúde, segurança e bemestar; garantir educação, formação e o desenvolvimento profissional; conquistar políticas sociais para mulheres chefes de família; igualdade política.

Entende-se que as conquistas necessárias requerem e tornam imperativa a mobilização do conjunto de indivíduos e instituições que compartilham do ideal de igualdade e da afirmação dos direitos humanos que poderá: concretizar a liberdade de escolher e agir; aumentar a autoridade das mulheres na tomada de decisões que afetam suas próprias vidas; reconhecer as mulheres como agentes de promoção econômica, social, e cultural; remover as barreiras impostas à participação política; ampliar as oportunidades, em termos quantitativos e qualitativos; ampliar e potencializar as habilidades; e melhorar as capacidades para o exercício de suas competências em diferentes campos de atuação, com valorização e respeito sob novas formas de sociabilidade sociopolítica.

Daí ser imperioso fortalecer a luta pela instituição de diversos princípios de empoderamento político, econômico e social das mulheres, como: o exercício de liderança em igualdade de gênero; isonomia salarial entre homens e mulheres de forma justa no trabalho; pleno acesso à saúde, à segurança e ao bem-estar; garantia de educação, formação e desenvolvimento profissional; conquista de políticas sociais para mulheres chefes de família; igualdade política. Para efetivar tais princípios, algumas alternativas devem ser implementadas: suporte público para as mulheres, especialmente as mães com filhos menores; garantia de cuidados públicos para as crianças pequenas (especialmente de 0 a 3 anos), como creches e universalização do ensino da pré-escola; medidas de compatibilização entre trabalho produtivo e reprodutivo, com corresponsabilidade entre os cônjuges no cuidado dos filhos; diversificação dos contratos de trabalho por tempo determinado e tempo parcial, que ajudem as mulheres a superar o trade off entre opção pela carreira profissional e opção pela maternidade.

Em relação ao acesso à educação aos segmentos em condição de exclusão, entende-se que tal ingresso no universo de cidadania proporciona as condições para que os alunos(as) desenvolvam sua capacidade dialógica, tomem consciência de seus próprios sentimentos e emoções e desenvolvam a capacidade autônoma/crítica de tomada de decisão em situações conflitantes do ponto de vista ético/moral. $\bigcirc$ desenvolvimento de projetos socioeducativos baseados em valores precisa ser 
multiplicado e deve enfatizar temas relevantes para a formação cidadã, como a abolição do trabalho infantil, a exploração sexual de crianças e adolescentes, a discriminação e brincadeiras jocosas.

Entretanto, entende-se que outras oportunidades também devem ser patrocinadas para o atendimento socioeducativo de adolescente em conflito com a lei, a promoção e defesa dos direitos de pessoas com deficiência e necessidades especiais. Essas ações em seu conjunto tecem uma rede socioeducativa formando embasamento para o aprendizado e à prática da cidadania, a partir de diversificadas ações pedagógicas, criativas, inovadoras, cooperativas e afirmativas, assim como apoiar a formação de competências dinâmicas compromissadas.

No mundo globalizado, o acesso à informação e ao conhecimento é decisivo para a construção de uma sociedade mais inclusiva e sustentável. $\bigcirc$ acesso à informação é um direito fundamental que permite que mulheres e homens entendam e participem na criação e no compartilhamento do conhecimento que precisam a fim de contribuir plenamente para a sociedade. $\bigcirc$ acesso à informação é uma condição para instrumentalizar e capacitar o cidadão (cidadania informada) que auxilia na responsabilização das instituições públicas, além de possibilitar aceder aos processos de inovação institucionais, tecnológicos, organizacionais, materiais e atitudinais. Para tal, a criatividade, o pensamento crítico, o letramento e as habilidades digitais são requisitos para alavancar as oportunidades de todos, com informações qualificadas para produção de conhecimento e exercício da cidadania.

No campo do conhecimento, as descobertas científicas nas áreas da engenharia genética e da biotecnologia conduzem avanços na proteção dos ecossistemas, na produção de transgênicos, seleção artificial, cruzamentos, além de conduzirem experiências que redundam em novos tratamentos, produtos, serviços e processos. Todavia, a vigência da Bioética que disciplina usos e previne riscos associada à difusão das informações para a sociedade como um todo são fatores fundamentais para a cidadania contemporânea.

No que tange às formas de combate à discriminação étnico-racial na contemporaneidade do mundo globalizado, faz-se urgente a construção do Protagonismo Social, em que o maior dilema e gigantesco desafio é a defesa dos princípios de lgualdade, Liberdade \& Solidariedade, a partir do combate às novas formas de imperialismo, de exploração, de políticas neoliberais. A ideia da dignidade e central para a compreensão dos direitos humanos e de sua universalidade para índios, negros, crianças, mulheres, presos, pobres, ou em relação à devastação do meio ambiente, haja vista que os direitos humanos superam as fronteiras jurídicas e a soberania dos Estados nacionais.

A realidade social e cultural é relacional, a organização social e a cultura são resultados de uma dinâmica de diferenciações e identificações, tanto no interior de um grupo ou segmento social quanto em relação aos outros grupos e ao conjunto da sociedade, como produto de um conflito simbólico entre os ocupantes de posições desiguais. Nesse cenário, o acesso ao conhecimento e à informação, o estímulo à 
convivência e o respeito à diversidade fomentam relações sociais entre indivíduos e grupos, e são fundamentais para explicitar as vontades políticas e dar visibilidade aos temas conflitantes. Assim como para fortalecer a vontade política na implementação de políticas sociais universais e para a consolidação de instituições inclusivas, propiciar ações regionais concertadas para rompimento dos padrões danosos de comportamentos estabelecidos, abrigando mudanças das normas sociais, culturais e políticas, que resultem em transformação nas atitudes e comportamentos das pessoas.

Na busca por um pacto local-global e para orientar a implementação dos Objetivos do Desenvolvimento Sustentável 2017-2021, foram estabelecidos Eixos e Resultados indicados do marco de parceria para o desenvolvimento sustentável, são eles:

I. EIXO PESSOAS: Sociedade inclusiva, equitativa e com plenos direitos para todos etodas

Resultado I: Desenvolvimento social fortalecido em todo o território, com a redução da pobreza, por meio do acesso a bens e serviços públicos de qualidade, especialmente nas áreas de educação, saúde, assistência social, segurança alimentar e nutricional e trabalho decente, com equidade e ênfase na igualdade de gênero, raça, etnia e geracional.

2. EIXO PLANETA: Gestão sustentável dos recursos naturais para a geração atual e às futuras.

Resultado 2: Modelos de governança participativa de gestão sustentável de recursos naturais e serviços ecossistêmicos, efetivos e fortalecidos, buscando territórios integrados, resilientes e inclusivos.

Resultado 3: Capacidades institucionais fortalecidas para promover as políticas públicas, sua coerência e implementação, para a gestão sustentável de recursos naturais e serviços ecossistêmicos, e o combate às mudanças do clima e seus efeitos adversos.

3. EIXO PROSPERIDADE: Prosperidade e qualidade de vida para todas as pessoas.

Resultado 4: Crescimento econômico inclusivo e ambientalmente sustentável, com diversificação produtiva, fortalecimento industrial, infraestrutura resiliente, aumento da produtividade e inovação, transparência, participação social e valorização das micro e pequenas empresas.

Resultado 5: Redução das desigualdades socioeconômicas e territoriais, com promoção do pleno emprego e do trabalho decente, garantia dos direitos sociais e trabalhistas, qualificação profissional, com especial atenção às pessoas em situação de maior vulnerabilidade.

4. EIXO PAZ: Sociedade pacífica, justa e inclusiva.

Resultado 6: Promoção de uma sociedade pacífica, justa e inclusiva, por meio de participação social, transparência e governança democrática, respeitando-se a laicidade do Estado e garantindo-se direitos humanos para todos e todas.

5. EIXO PARCERIAS: Parcerias múltiplas para implementação da agenda de desenvolvimento sustentável. 
Resultado 7: Parcerias estratégicas estabelecidas para fortalecer e promover a cooperação internacional e contribuir para a redução das desigualdades dentro dos países e entre eles.

Um dos grandes desafios é a dificuldade para se estabelecer um pacto global que tornaria a prevenção prioridade para todos e fortaleceria a governança ambiental em todos os níveis. A superação dos desafios do desenvolvimento humano é complexa e envolve reformas não apenas nacionais, mas também em instituições globais, como os mercados, a sociedade civil e os organismos multilaterais. Dentre as reformas, a regulação de investimentos e mercados justos, um sistema de migração justo, mudanças no padrão de produção e consumo com a promoção de consumo e produção sustentáveis, o investimento em práticas de gestão e manejo de recursos com redução do desperdício pelo compromisso cidadão com mudanças de valores e estilos de vida, pela prática de ações colaborativas para desenvolver soluções e priorizar investimento em produção e consumo limpos.

Os Gráficos 3 e 4 indicam um conjunto de articulações necessárias de serem conduzidas pelos países para a consecução das metas do desenvolvimento sustentável como parte dos esforços da Agenda 2030, dos Objetivos do Desenvolvimento Sustentável.
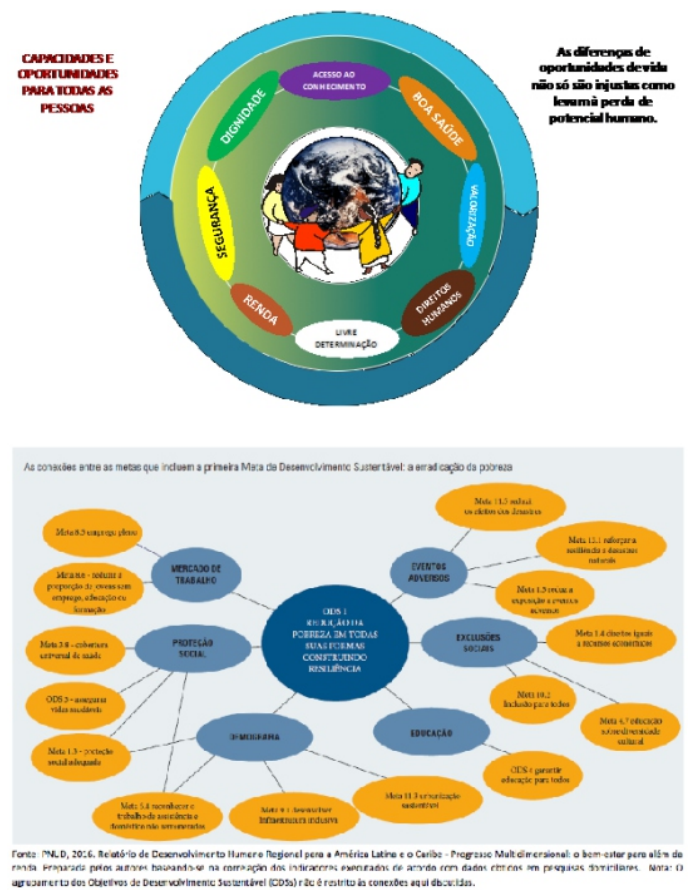
A título de ilustração, vale citar o poema Quem é o verdadeiro deficiente?

\begin{abstract}
"Se você deixa de ver a pessoa, vendo apenas a deficiência quem é o cego? Se você deixa de ouvir o grito do seu irmão para a justiça, quem é o surdo? Se você não pode comunicar-se com sua irmã e a separa, quem é o mudo? Se sua mente não permite que seu coração alcance seu vizinho, quem é o deficiente mental? Se você não se levanta para defender os direitos de todos, quem é o aleijado? A atitude para com as pessoas deficientes pode ser nossa maior deficiência... Ea sua também" (Autor desconhecido)
\end{abstract}

\title{
5 CONSIDERAÇÕES FINAIS
}

A luta pela igualdade social, em sua legitimidade, representa a busca justificada do direito de usufruir da vida em sociedade com dignidade, como condição inerente de cidadania. A igualdade é uma condição que requer o exercício ativo da solidariedade (pessoal e coletiva), o exercício da participação política cidadã, da requisição pela vigência de um sistema econômico justo e inclusivo.

A solidariedade é parte integrante da cidadania, via da participação dos cidadãos nas instituições, constituindo o espaço de articulação entre Estado e sociedade. O grau de aprofundamento dos desafios políticos, sociais e ambientais na contemporaneidade impõe caráter de urgência nas ações para superar as condições de adversidades ambientais, e os riscos e vulnerabilidades geradas pela pobreza material e simbólica que põem em risco a própria civilização. É preciso superar a cultura e a naturalização da violência presente em nosso cotidiano, o desafio é não desperdiçar as possibilidades, adotar princípios éticos, práticas sustentáveis, cultivar valores, assumir os compromissos com o exercício de uma nova sociabilidade política.

\section{REFERÊNCIAS}

ALMEIDA, F. L. A inclusão social e o reconhecimento da universalidade dos direitos humanos: da tolerância às ações afirmativas. In LIVIANU, R., Cood. Justiça, cidadania e democracia [online]. Rio de Janeiro: Centro Edelstein de Pesquisa Social, 2009.

ARAÚjO, Ulisses F. [et al..]. Programa Ética e Cidadania: construindo valores na escola e na sociedade : inclusão e exclusão social / organização FAFE - Fundação de Apoio à Faculdade de Educação (USP), Brasília:Ministério da Educação, Secretaria de Educação Básica, 2007. 4v.

LIRA, T. de Melo \& CHAVES, Ma. do P. Socorro Rodrigues. Comunidades ribeirinhas na Amazônia: organização sociocultural e política. Interações, Campo Grande, MS, v. 17 , n. I, p. 66-76, jan./mar. 2016. 
ONU Brasil. A ONU no Brasil 2012-1016, 2017.

ONU Mulher. Retratos das Desigualdades de Gênero e Raça, 2017.

ONU. Relatório Mundial das Nações Unidas sobre Desenvolvimento dos Recursos Hídricos. Água para um Mundo Sustentável, 2015.

ONU Brasil. Documentos Temáticos: Objetivos de Desenvolvimento Sustentável I 2 . $3 \cdot 5 \cdot 9 \cdot \mid 4$. Brasília, 2017

ONU. Direitos Humanos. Guia prático para a sociedade civil. O Campo de ação da Sociedade Civil e o Sistema dos Direitos Humanos das Nações Unidas, 2014.

ONU. Declaração Universal dos Direitos Humanos.

NOBRE, Edna Luiza. Direitos Humanos e a Inclusão Social: o Resgate da Cidadania através da Assistência Social - Acertos e Desacertos. Rev. Fac. Dir. Sul de Minas, Pouso Alegre, v. 27, n. 1:21-58, jan./jun. 201 I.

Word Economic Forum. The Global Gender Gap Report, 2016. 
